\title{
Evaluation of Real Water Losses and the Failure of Urban-Rural Water Supply System
}

\author{
Joanna Gwoździej-Mazur ${ }^{*}$, Kamil Świętochowski \\ 1 Department of Water Supply and Sewage Systems, Faculty of Civil Engineering and Environmental Sciences, \\ Bialystok University of Technology, ul. Wiejska 45A, 15-351 Bialystok, Poland \\ * Corresponding author's e-mail: j.mazur@pb.edu.pl
}

\begin{abstract}
The topic of failures and water losses in the urban-rural water supply network was discussed. The purpose of the work was to assess the level of real water losses and the failure rate of the urban-rural water supply network in 2010-2016. The article's introduction contains the information on the types and causes of breakdowns in the water supply network. The life cycle of the leakage from its inception to its removal was also described. Next, the methodology and indicators for assessing actual losses in the water supply network were presented according to the guidelines of the International Water Association (IWA), i.e. ILI, CARL, UARL, RLB and water balance. The material and methods chapter describes how to calculate the failure rate. On the basis of the literature review, a method of assessing the failure of the water supply network and the level of actual water losses was presented. The research part presents the results of the water losses indicators values and assesses them against the literature data for the entire urban-rural system. The results of the failure of the water supply of the urban area and the rural area were also presented and compared with the literature data. A method of calculating limit values of the failure intensity index for the entire water supply system was also proposed. The changes in the intensity of failure occurrence during the year were presented. The object described in the studies achieved the A rating according to the classification of ILI and RLB values throughout the entire analysis period (2010-2016). Failure intensity in the analyzed period exceeded the average values calculated for water supply networks in Poland many times. The values in individual cases exceeded the limit values specified in the literature.
\end{abstract}

Keywords: water losses, water supply system failures, urban-rural water supply system, IWA water balance, infrastructure leakage index

\section{INTRODUCTION}

In the process of reducing water losses in the water supply network, an important element is the proper understanding of the water supply network. Historical data regarding the number and type of failures on the water supply network, collecting the data on the location of the failure, checking the balance of system input volumeauthorized consumption-water losses, calculating the infrastructure leakage index, knowing where is the limit of profitability of investments aiming at limiting real water losses are helpful in this respect. This article analyzes the urban-rural water supply network. The infrastructure leakage index (ILI) was calculated and the amount of unavoidable losses was checked. In the next part, the level of damage intensity was checked in the urban, rural and the entire system and the results obtained were compared with the literature data (Bergel, 2012, Bergel et al., 2013, Kwietniewski, 2011, Kwietniewski \& Rak, 2010] and the guidelines of PN-EN 60300-3-4: 2008. It was also checked in which periods of the year do the most frequent and the least frequent failures occur, and thus when the intensity of activities reducing the losses of water should be increased, e.g. acoustic leak searching.

The damage to water pipes can be grouped due to:

a) the cause of damage, e.g. conduit freezing, mechanical damage as a result of construction 
works, material defect, corrosion, high pressure in the conduit, etc. [Pilcher, 2013,]

b) type of damage, e.g. transverse fracture, longitudinal fracture, pipe socket damage, etc. [Berger \& Ways, 2003],

c) damaged conduit element, e.g. valve failure, pipe failure, etc.,

Failure of the water supply network, depending on the type of damage, the size of the damage and the pressure in the network, is characterized by different flow of water from the pipe. The larger the leak hole and the higher the pressure, the greater the water outflow from the pipe through the leak.

An important factor affecting the amount of real water losses in the water supply system is the time from the moment of leakage to its detection, location and repair - variant A in Figure 1. Reducing the time of failure significantly decreases the amount of real water loss from failure. The greatest profit can be obtained at the stage of failure detection and its location - variant B in Figure 1 [Farley, 2003, Hamilton \& Charalambous, 2013]. The failure repair time, compared to the time of failure detection and its location, is often negligible. A more important issue during repair is ensuring the quality of the work done so that it does not cause further failures in the future [Thorrnton et al., 2008].

The calculation method of ILI is presented in the formula:

$$
I L I=\frac{C A R L}{U A R L}
$$

where: $C A R L$ - the volume of Current Annual Real Losses, $\mathrm{m}^{3} \cdot$ year $^{-1}$, UARL - the volume of Unavoidable Annual Real Losses, $\mathrm{m}^{3} \cdot \mathrm{year}^{-1}$.
Unavoidable Annual Real Losses (UARL) is the volume of water per unit of time, which for technical and economic reasons is practically impossible to eliminate at a given time from the water supply network [Lambert et al., 1999]. The method of calculating the volume of Unavoidable Annual Real Losses is presented in the formula:

$$
\begin{aligned}
U A R L=[ & \left.18.0 \cdot L_{M}+25.0 \cdot L_{P}+0.8 \cdot N_{C}\right] \cdot \\
& \cdot 0.365 \cdot P\left[\frac{m^{3}}{\text { year }}\right]
\end{aligned}
$$

where: $L_{M}-$ length of distribution and main pipes, $\mathrm{km}$,

$L_{P}-$ length of house water service connection, $\mathrm{km}$,

$N_{C}-$ number of service connection, number,

18.0 - the volume of Unavoidable Annual Real Losses in the main and distribution pipes, $\mathrm{dm}^{3} \cdot \mathrm{km}^{-1} \cdot \mathrm{d}^{-1} \cdot \mathrm{m} \mathrm{H}_{2} \mathrm{O}^{-1}$,

25.0 - the volume of Unavoidable Annual Real Losses in the house water service connection, $\mathrm{dm}^{3} \cdot \mathrm{km}^{-1} \cdot \mathrm{d}^{-1} \cdot \mathrm{m} \mathrm{H}_{2} \mathrm{O}^{-1}$,

0.8 - the volume of Unavoidable Annual Real Losses in the house water service connection, $\mathrm{dm}^{3} \cdot \mathrm{km}^{-1} \cdot \mathrm{d}^{-1} \cdot \mathrm{m} \mathrm{H}_{2} \mathrm{O}^{-1}$, $P$ - average pressure in water system network, $\mathrm{m}_{2} \mathrm{O}$.

Water volume, classified as real losses, results from the water balance made according to the IWA guidelines [Alegre et al., 2000]. The volume of real water losses is the volume of Non-Revenue Water (NRW) less the Unbilled Authorized Coinsumption (metered and unmetered) and apparent losses (metering inaccuracies, unauthorized consumption) [Alegre et al., 2000].

The IWA guidelines regarding the assessment of the water supply network also point
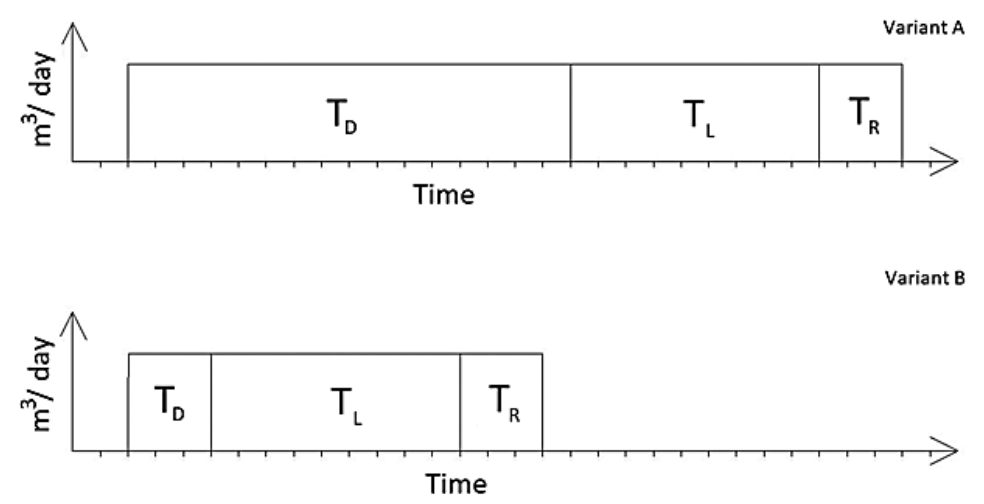

Figure 1. Leakage life time [Farley, 2003] 
to other indicators, e.g. Real Leakage Balans (RLB) [Alegre et al., 2000, Farley, 2008]. It is the amount of water losses per $1 \mathrm{~km}$ of water supply network (main and distribution) per day [Lambert et al., 1999]. The calculation of the RLB indicator depends on the number of connections per $1 \mathrm{~km}$ of distribution and main network. Therefore, the formulas for calculating the RLB take the following forms:

with density of connections less than 20 per $\mathrm{km}$ of mains:

$$
R L B=\frac{C A R L \cdot 1000}{(M+R) 365}\left[\frac{d m^{3}}{\mathrm{~km} \cdot \mathrm{day}}\right]
$$

with density of connections greater than 20 per $\mathrm{km}$ of mains:

$$
R L B=\frac{C A R L \cdot 1000}{L_{P} \cdot 365}\left[\frac{d m^{3}}{\mathrm{~km} \cdot d a y}\right]
$$

\section{MATERIAL AND METHODS}

The International Water Association (IWA) guidelines [Lambert et al., 2014] were used to calculate and evaluate the Infrastructure Leakage Index (ILI) and The Unavoidable Annual Real Losses (UARL). On the basis of the value of ILI and RLB, it is possible to assess the technical condition of the water supply network using the data from Table 1.

Failure frequency index was calculated based on the formula (5)[Kwietniewski \& Rak, 2010]:

$$
\lambda(\Delta t)=\frac{n(\Delta t)}{L \times \Delta t}
$$

where: $\lambda(\Delta t) \quad-$ unit failure intensity, failure $\cdot \mathrm{km}^{-1} \cdot \mathrm{year}^{-1}$,

$n(\Delta t)$ - number of failures within time interval $\Delta \mathrm{t}$,

$L-$ length of pipes tested within time interval $\Delta \mathrm{t}, \mathrm{km}$,

$\Delta t$ - considered time inter, year.

The evaluation of the intensity of damage to water pipes was based on the guidelines contained in the PN-EN 60300-3-4: 2008 standard and on the values of the average damage intensity indicators described in the Bergel's paper from 2012 [Bergel, 2012]. Additionally, the limit values of the failure intensity index were used based on Kwietniewski's recommendations [Kwietnewski, 2008]:

a) low failure, when $\lambda \leq 0.1$, b) average failure, when $0.1<\lambda \leq 0.5$,

c) high failure, when $\lambda>0.5$.

Average and maximum values of failure intensity index were presented in Table 2 .

\section{RESULTS AND DISCUSSION}

The research object is an urban-rural water supply network located in the central part of Poland. The water supply system supplies water to approximately 12,000 inhabitants, $25 \%$ of whom live in the urban area. The water supply network currently has approx. $264 \mathrm{~km}$ of main and distribution pipes as well as over $70 \mathrm{~km}$ of water connections. The water supply pipes in the urban area constitute less than $7 \%$ of all pipes. The share of rural and urban area in the length of main pipes, distribution cables and connections is presented in Figure 2.

The water supply network is divided into 2 zones, supplied from separate water sources (SUW). The network is separated by means of gate valves and has no flow measurement points between the zones. If the zones are connected for

Table 1. Physical loss target matrix (Farley, 2008)

\begin{tabular}{|c|c|c|}
\hline \multirow{2}{*}{$\begin{array}{c}\text { Technical } \\
\text { performance category }\end{array}$} & ILI & $\begin{array}{c}\text { Physical losses [litres/ } \\
\text { connection/day] } \\
\text { (when the system } \\
\text { is pressured) } \\
\text { at an average } \\
\text { pressure of 50 m }\end{array}$ \\
\hline \multirow{5}{*}{ Developed countries } & $1-2$ & $<125$ \\
\cline { 2 - 3 } & $2-4$ & $125-250$ \\
\cline { 2 - 3 } & $4-8$ & $250-500$ \\
\hline \multirow{5}{*}{ Developing countries } & $>8$ & $>500$ \\
\cline { 2 - 3 } & $1-4$ & $<250$ \\
\cline { 2 - 3 } & $4-8$ & $250-500$ \\
\cline { 2 - 3 } & $>16$ & $500-1000$ \\
\hline
\end{tabular}

\begin{tabular}{|c|c|c|}
\hline Indicator & $\begin{array}{c}\text { Maximum value } \\
\text { [Pietrucha-Urbanik \& } \\
\text { Studziński, 2016, } \\
\text { PN-IEC 60300-3-4:2008, } \\
\text { Rak, 2007] }\end{array}$ & $\begin{array}{c}\text { Average value in } \\
\text { Poland [Bergel, } \\
\text { 2012] }\end{array}$ \\
\hline$\lambda_{\text {main }}$ & 0.3 & 0.26 \\
\hline$\lambda_{\text {distribution }}$ & 0.5 & 0.17 \\
\hline$\lambda_{\text {service }}$ & 1 & 0.49 \\
\hline $\begin{array}{l}\text { conmection } \\
\lambda_{\text {system }}\end{array}$ & - & 0.27 \\
\hline
\end{tabular}

Table 2. The maximum and average values of the intensity of damage to the pipes 


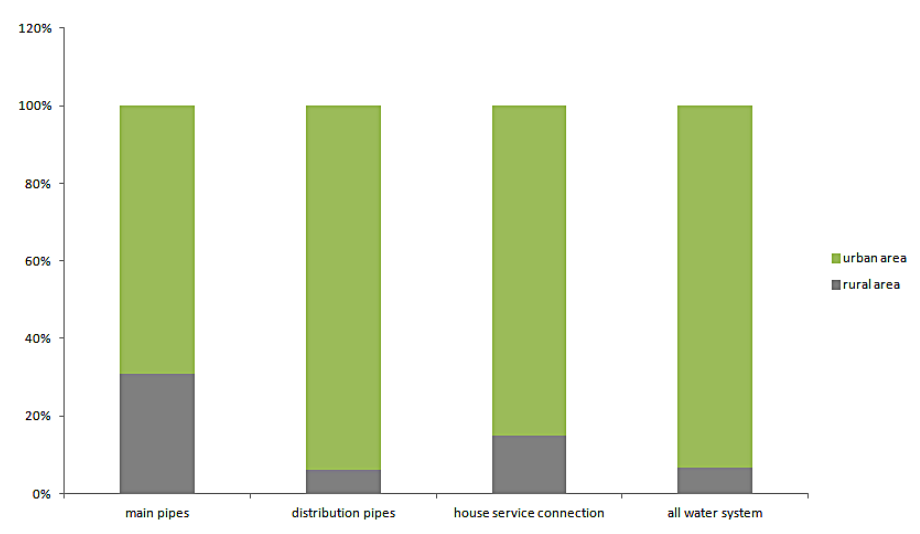

Figure. 2. Share of urban and rural areas in the water supply network

the time of removing the water supply failure in one of the zones or its part, it is not possible to make a correct balance of the water injected and sold. Therefore, it is not possible to calculate the water loss rates separately for urban and rural areas. It was decided to present the ILI indicator for the entire water supply system. The failure analysis and assessment were carried out separately for the rural and urban area and for the entire urbanrural water supply system.

The ILI values fluctuated from 0.68 to 2.48 in the years 2010-2016. ILI fell below 2 in 2012 and has remained below 1 since 2014. ILI has been decreasing systematically in the period 20102014. The level of real water losses according to the ILI index value is assessed as very good in the years 2010-2016 (grade A for ILI $<2$ in developed countries) [Lambert et al., 2014]. The level of actual losses was below 1 in 2013-2016, i.e. it fell below the economically justified threshold for reducing real water losses. The ILI value has been growing since 2015 , but it remains at the level of
A. The effect of improving the network by intensifying operations and investments (a strong decrease in ILI value), and then maintaining investments in the network at an economically justified level (slow increase in ILI value) can be seen. The UARL value for the entire system varies from 125,000 to $150,000 \mathrm{~m}^{3}$ year $^{-1}$ in the analyzed system. The urban area accounts for 8 to $10 \%$ of the UARL value of the entire water supply system.

The research object has a density of connections below 20. The formula (3) was used to calculate the RLB indicator. The obtained results are presented in Figure 4. Table 1 gives the limits for physical loss for connection per day. If the formula (4) were used in the tested object, the values of approx. $100 \mathrm{dm}^{3} \cdot$ connection $^{-1} \cdot$ day $^{-1}$ would be obtained, thus achieving the A rating. Both the ILI and RLB values obtained indicate that the tested water supply system achieves the A rating.

Table 3 presents the results of the calculated failure intensity index of the main pipes, distribution pipes and connections in the years 2010-2017

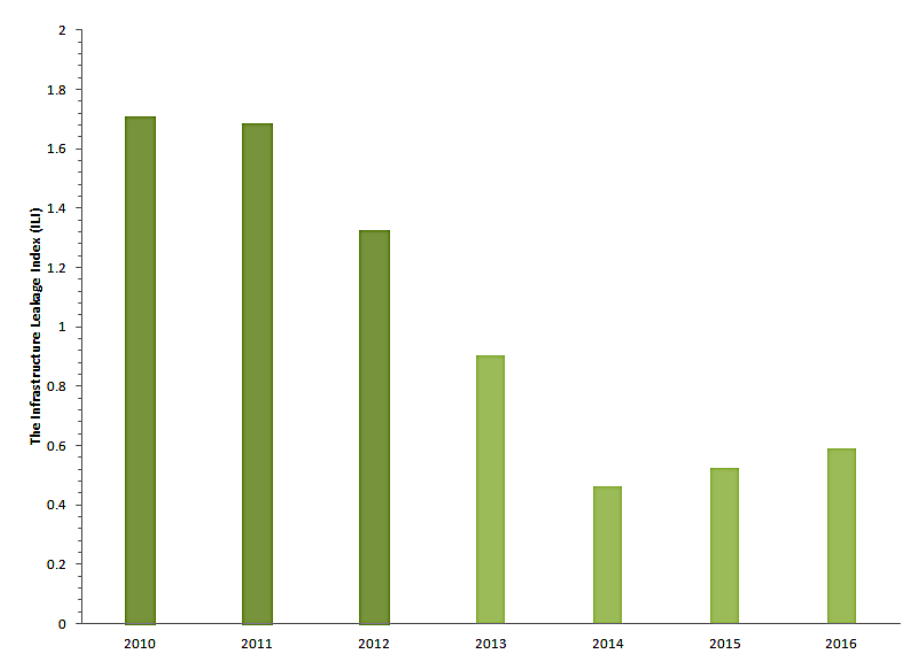

Figure 3. The value of ILI in 2010-2016 


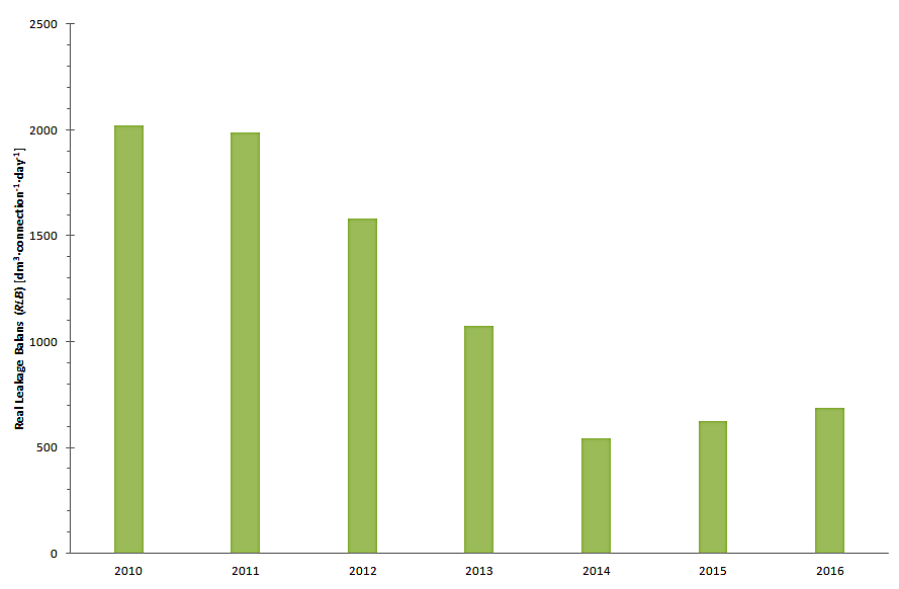

Figure 4. The value of RLB in 2010-2016

Table 3. Values of intensity indicators of pipes damage in the urban area

\begin{tabular}{|l|c|c|c|c|c|c|c|c|}
\hline \multicolumn{1}{|c|}{ indicator } & 2010 & 2011 & 2012 & 2013 & 2014 & 2015 & 2016 & 2017 \\
\hline$\lambda_{\text {main }}$ & 0.50 & 0.00 & 0.00 & 0.00 & 0.00 & 0.00 & 0.00 & 0.00 \\
\hline$\lambda_{\text {distribution }}$ & 0.27 & 0.13 & 0.20 & 0.33 & 0.00 & 0.00 & 0.00 & 0.06 \\
\hline$\lambda_{\text {service connection }}$ & 0.94 & 0.99 & 0.86 & 0.89 & 0.89 & 0.09 & 0.88 & 0.86 \\
\hline
\end{tabular}

in the urban area. There were no failures on the main pipes except for 2010, when 1 failure occurred, which resulted in obtaining the value of $\lambda=0.50$ failure $\cdot \mathrm{km}^{-1} \cdot \mathrm{year}^{-1}$, thus exceeding the allowable value [PN-IEC 60300-3-4:2008] and was higher than the average for Poland [Bergel, 2012]. The failure intensity index values for distribution pipes in the urban area varied from 0.00 to 0.33 failure $\mathrm{km}^{-1} \cdot \mathrm{year}^{-1}$. In the case of distribution pipes, the permissible values were exceeded once, i.e. in 2013, and in half of the cases the average value for Poland was exceeded [Bergel, 2012].

The calculated values of the failure intensity index for connections changed mainly from 0.86 to 0.99 failure $\mathrm{km}^{-1} \cdot \mathrm{year}^{-1}$. The failure intensity index value was $\lambda=0.09$ failure $\mathrm{km}^{-1}$.year ${ }^{-1} \mathrm{In}$ 2015. The obtained index values for connections did not exceed the permissible values [Kwietniewski \& Rak, 2010, PN-IEC 60300-3-4:2008] but were almost twice as high as the Polish average of $\lambda=0.49$ failure $\mathrm{km}^{-1} \cdot$ year $^{-1}$ [Bergel, 2012].

Table 4 presents the results of the calculated failure intensity index for main and distribution pipes as well as connections in the years 2010-2017 in the rural area. There were no failures on the main pipes, and thus $\lambda=0.00$ failure $\cdot \mathrm{km}^{-1} \cdot \mathrm{year}^{-1}$ was obtained in each year.

The failure intensity index values for distribution pipes in the rural area varied from 0.00 to 0.13 failure $\cdot \mathrm{km}^{-1} \cdot \mathrm{year}^{-1}$. The permissible values specified in the standard and literature were not exceeded for distribution pipes.

The calculated values of the failure intensity index for connections changed mainly from 0.18 to 0.20 failure $\mathrm{km}^{-1}$.year ${ }^{-1}$. The obtained index values for connections did not exceed the permissible values described in the standard and literature.

On the basis of the literature data [Bergel, 2012, Kwietniewski \& Rak, 2010, PN-IEC 60300-3-4:2008] the limit value of the failure intensity index for the entire water supply system was determined by the formula:

$$
\lambda_{\text {sieci }}=\left(0.3 \cdot L_{M}+0.5 \cdot L_{R}+1.0 \cdot L_{P}\right) / \sum L_{i}
$$

where: $L_{M}-$ lenght of main pipes, $\mathrm{km}$, $L_{R}$ - lenght of distribution pipes km, $L P$ - length of water connection service, $\mathrm{km}$,

Table 4. Values of failure intensity index of pipes damage in the rural area

\begin{tabular}{|l|c|c|c|c|c|c|c|c|}
\hline \multicolumn{1}{|c|}{ indicator } & 2010 & 2011 & 2012 & 2013 & 2014 & 2015 & 2016 & 2017 \\
\hline$\lambda_{\text {main }}$ & 0.00 & 0.00 & 0.00 & 0.00 & 0.00 & 0.00 & 0.00 & 0.00 \\
\hline$\lambda_{\text {distribution }}$ & 0.04 & 0.02 & 0.03 & 0.13 & 0.03 & 0.00 & 0.01 & 0.02 \\
\hline$\lambda_{\text {service connection }}$ & 0.20 & 0.20 & 0.19 & 0.19 & 0.19 & 0.19 & 0.18 & 0.18 \\
\hline
\end{tabular}




$$
\Sigma L_{i}-\text { sum of all water pipes lenght, } \mathrm{km} \text {. }
$$

The limit value of the failure intensity index for the entire system is 0.60 failure $\cdot \mathrm{km}^{-1} \cdot \mathrm{year}^{-1}$. For the urban area, the maximum value of the failure intensity index is 0.67 failure $\mathrm{km}^{-1} \cdot \mathrm{year}^{-1}$, and in the rural area 0.59 failure $\mathrm{km}^{-1} \cdot \mathrm{year}^{-1}$. The calculated values of the failure intensity index for the urban area changed from 0.30 to 0.64 failure $\mathrm{km}^{-1}$ year 1 and did not exceed the calculated maximum value. The calculated values of the failure intensity index for the rural area varied from 0.06 to 0.14 failure $\mathrm{km}^{-1} \cdot \mathrm{year}^{-1}$ and did not exceed the calculated maximum value. The calculated values of the failure intensity index for the entire water supply network varied from 0.08 to 0.16 failure $\cdot \mathrm{km}^{-1} \cdot \mathrm{year}^{-1}$ and did not exceed the calculated maximum value.
The number of failures during the year in the urban and rural areas is presented in figure 5 . The most failures in the urban water supply network in 2010-2017 were recorded in September, July and May. The most failures of the rural water supply network in 2010-2017 were recorded in September and November. The month when most emergencies occurred in the analyzed water supply system is September. The fewest failures of the urban water supply network in 2010-2017 were recorded in February and March. The fewest failures in the rural water supply network in 2010-2017 were recorded in February. The month with fewest emergencies in the analyzed water supply system is February.

The changes in the average monthly damage intensity in the urban area, the rural area and

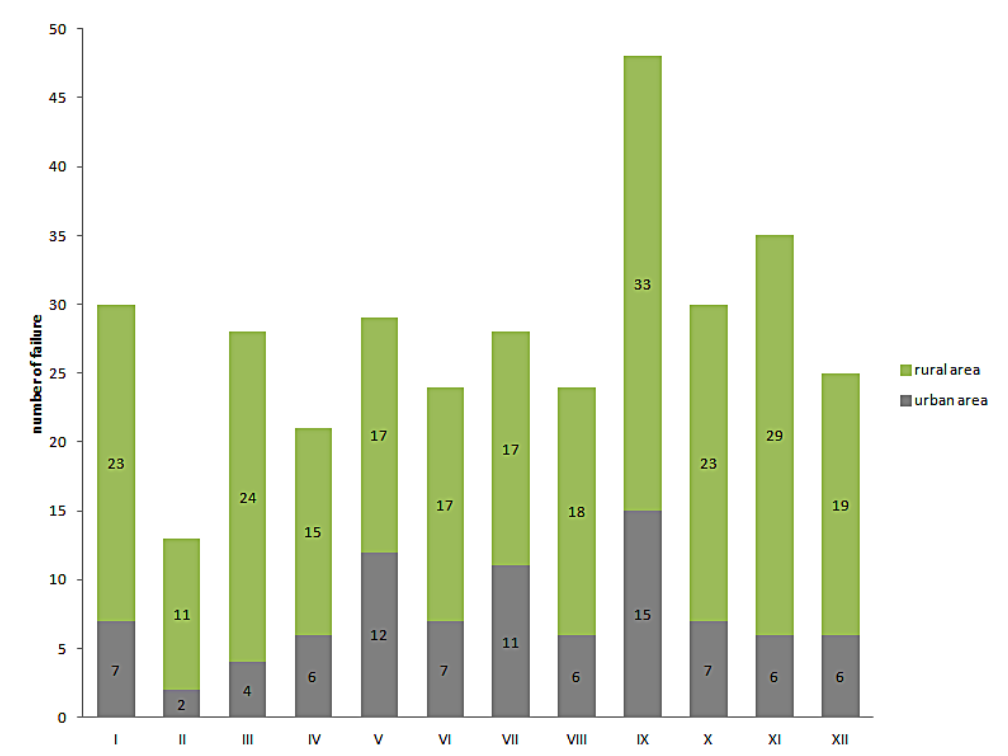

Figure 5. Total number of failures of the water supply network in 2010-2017

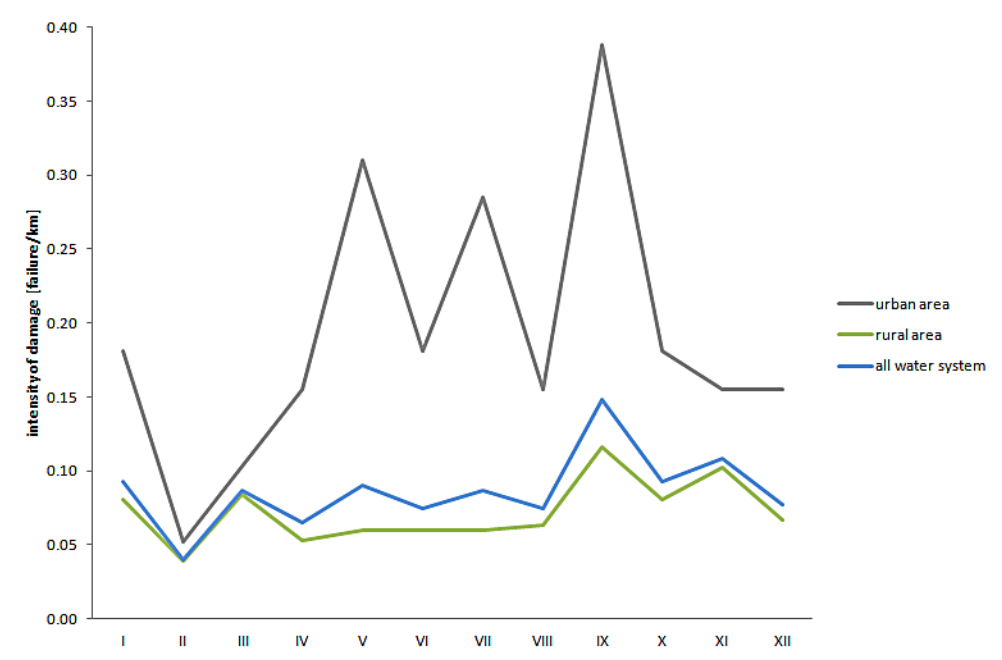

Figure 6. Average intensity of damage to the water supply network in 2010-2017 
the entire water supply system are presented in Figure 6 . The average monthly damage intensity in the urban area varies from 0.05 in February to 0.39 failure $\mathrm{km}^{-1}$ of the network in September. The average monthly damage intensity in a rural area varies from 0.04 in February to 0.12 failure $\mathrm{km}^{-1}$ of the network in September. The average monthly damage intensity for the entire water supply system varies from 0.04 in February to 0.15 failure $\mathrm{km}^{-1}$ of the network in September.

\section{CONCLUSION}

The research object obtained the A rating in terms of ILI and RLB values. The level of actual water losses, despite the upward trend (comparison of successive years), remained at an acceptable level in recent years. In the future, the research facility could be re-analyzed to check the current level of ILI and RLB, as well as examine what factors affected the deterioration or improvement of the results obtained in subsequent years.

In the examined period, the municipal water supply network of the evaluation object was characterized by single exceeding of the limit values of failure intensity index for main and distribution pipes in urban areas. The values of failure intensity index for the distribution pipes and connections were higher than the average values of these index in Poland in most cases. The limit values of failure intensity index were not exceeded in the rural area. Water supply connections are the most unreliable element of the water supply network in both urban and rural areas. When analyzing the failure of a water supply network, the calculated value of the failure intensity index cannot be considered as reliable, amd the result obtained in relation to the length of a given type of pipe should always be checked, which applies to the value $\lambda=$ 0.50 failure $\mathrm{km}^{-1}$.year ${ }^{-1}$ for the urban main pipe (1 failure per $2 \mathrm{~km}$ of pipe in one year). A method of calculating the limit value for the failure intensity index for the entire water supply system depending on the network size was proposed. The calculated values of the failure intensity index for the whole system did not exceed the limit values of the indicator either in the rural area or in the urban area. The most failures in the tested water supply network were recorded in September and the fewest in February. In the urban area the most failures were registered in May, July and September.

\section{Acknowledgements}

The studies were carried out in the framework of working No. WZ/WBiIŚ/02/2019 and financed from the funds for science MNiSW.

\section{REFERENCES}

1. Alegre H., Hirnir W., Baptista J.M., and Parena R., Performance Indicators for Water Supply Services, IWA Manual Best Practice, first edition, IWA Publishing, London, 2000.

2. Bergel T. 2012. Failure rate of water systems of small group water supply networks in Poland. Gaz, Woda i Technika Sanitarna, 12,536-538

3. Bergel T., Kaczor G., Bugajski P. 2013. Technical conditions of water supply networks in small waterworks of the małopolska and podkarpackie voivodeships. Infrastructure and ecology of rural areas, $\mathrm{Nr}$ 3/IV/2013, 291-304

4. Berger M., Ways M. 2003. Searching for leaks in water supply networks. Guide. Seidel-Przywecki Publishing House, Warsaw.

5. Farley M., 2003 . Non-Revenue Water-International Best Practice for Assessment, Monitoring and Control, 12th Annual CWWA Water, Wastewater m\& Solid Waste Conference, Bahamas, (download from www.liemberger.cc)

6. Farley M. 2008. The Manager's Non-Revenue Water Handbook. USAID

7. Hamilton S., Charalambous B. 2013. Leak Detection. Technology and Implementation, London

8. Kwietniewski M. 2011, Unreliability of water supply and wastewater infrastructure in poland based on field tests, XXV Scientific and Technical Conference in Międzyzdroje, I:127-141

9. Kwietniewski M., Rak J. 2010. Reliability of water supply and sewage infrastructure in Poland. PAN, Warsaw

10. Lambert A.O., Brown T.G., Takizawa M., and Weimer D., A Review of Performance Indicators for Real Losses from Water Supply Systems, AQUA, 48 (6), ISSN 0003-7214, 1999, pp. 227- 23

11. Lambert and others. 2014. 14 Years Experience of using IWA Best Practice Water Balance and Water Loss Performance Indicators in Europe. http://www. leakssuite.com/outreach/free-papers

12. Pietrucha-Urbanik K., Studziński A. 2016. Selected Issues of Costs and Failure of Pipes in an Exemplary Water Supply System. Annual Set The Environment Protection, 18, 616-627

13. Pilcher R. 2003. Leak detection practices and techniques: a practical approach. WATER21,44-45.

14. PN-IEC 60300-3-4:2008

15. Rak, J.R. 2007. Some aspects of risk management in waterworks. Annual Set The Environment Protection, 29, 61-64.

16. Thornton J., Sturm R., Kunkel G. 2008. Water Loss Control. McGraw-Hill Education 